\title{
Minería ilícita en el Parlamento Peruano: Análisis sobre el impacto del financiamiento de la campaña de Fuerza Popular en las elecciones generales del 2016
}

\section{Illegal mining in the Peruvian Parliament: An analysis of the impact of the financing of the Fuerza Popular campaign on the 2016 general elections}

\section{Penélope Soleil Brou González (*) \\ Pontificia Universidad Católica del Perú \\ ORCID: 0000-0002-0689-328X}

Fecha de recepción: 20 de mayo

Fecha de aceptación: 1 de agosto

ISSN en línea: 2415-2498

Brou González, P. (2019) « Minería ilícita en el Parlamento Peruano: Análisis sobre el impacto del financiamiento de la campaña de Fuerza Popular en las Elecciones Generales del 2016». Politai: Revista de Ciencia Política, Año 10, primer semestre, № 19: pp.77-97

DOI: https://doi.org/10.18800/politai.201901.003

* Estudiante de Ciencia Política y Gobierno en la Pontificia Universidad Católica del Perú. Investigadora en el Grupo de Investigación de Partidos Políticos y Elecciones (GIPE) con interés en la lucha contra la corrupción, sistemas electorales y temas ambientales. 


\section{Sumilla}

Las actividades ilícitas que reúnen grandes cantidades de dinero se ven vinculadas por medio de actividades como el lobby y el financiamiento de campaña, y actividades similares, con diversos sectores estatales, haciendo parecer ser dejadas de lado a la hora de analizar a profundidad el impacto del dinero en la política. Siguiendo esta premisa, la presente investigación se enmarca dentro de los estudios sobre las estrategias políticas de grupos de minería ilícita, en particular en la región peruana de Madre de Dios. El artículo pretende realizar un estudio exploratorio sobre la relación entre grupos de minería ilegal e informal y el partido que obtuvo la mayor votación en el Poder Legislativo en las elecciones generales del 2016, Fuerza Popular, argumentando que, en un escenario electoral personalista, donde los partidos políticos operan en forma de constelaciones de intereses en vez de una forma programática, el financiamiento de las campañas políticas permite formar nexos entre los financistas y los candidatos políticos. En el caso del Poder Legislativo, una vez obtenidos los curules, dicho nexo ha propiciado la discusión de un proyecto de ley, que beneficiaría los intereses económicos de las mineras ilícitas, abordando temas como la no formalización, o la minimización de condenas de dichos grupos. Esta actividad se mantiene enraizada en nuestro país y se conecta con otras actividades ilícitas como el narcotráfico o la trata de personas. Por lo que, es de suma importancia analizar el vínculo que mantiene con la política peruana, y así develar las formas en la que dichas actividades permanecen al margen de la ley.

Palabras clave: Lobby, minería ilícita, poder legislativo, financiamiento político 


\section{Abstract}

Illicit activities that collect large amounts of money are linked through lobby, campaing financing, and similar activities, with various state sectors and seem to be left aside when analyzing the impact of money on politics. Following this premise, this research is framed within the studies on the political strategies of illegal mining groups in particular in the Madre de Dios Region. The article intends to carry out an exploratory study on the relationship between illegal and informal mining groups and the political party that obtained parliamentary majority in the 2016 general election, Fuerza Popular, arguing that in a personalistic electoral scenario marked by political parties that far from operating with a fixed programmatic line they do in the form of constellations of interests, the campaign financing allow to form nexuses between the financiers and the political candidates. In the case of the Legislative Branch, once the seats have been obtained, this link has led to the discussion of legislative bill that would benefit the economic interests of the illicit miners, which address issues such as non-formalization or the minimization of condemnation of these groups. Being an activity that, being rooted in our country is connected with other illicit activities such as drug trafficking or human trafficking, it is very important to analyze the link it maintains with peruvian politics to reveal the ways in which these activities remain outside the law.

Keywords: Lobby, illicit mining, legislative power, political financing 


\section{Introducción}

En el marco de un país tan plural como el Perú, que presenta una latente falta de representación y cada vez mayor corrupción, analizar el impacto que tuvieron los grupos de poder económico como financistas en las campañas electorales una vez acabadas las elecciones, es cuanto menos relevante. La presente investigación se propone analizar el impacto de estos actores al momento de tomar decisiones en el Poder Legislativo; se ha seleccionado como ejemplo el caso de las minerías informales -como ejemplo de financista- y Fuerza Popular -como el partido político receptor de los fondos y posterior defensor de intereses de dicho grupo. El análisis parte de una revisión teórica sobre el financiamiento y los diversos mecanismos identificados en el caso de estudio. Luego, se realiza un análisis de las vulnerabilidades del país frente a economías ilícitas, en particular del caso de la minería, y de sus vínculos con este partido. Finalmente, se presenta una revisión de su reflejo en un proyecto de ley presentado por una congresista de la bancada de dicha agrupación política en el período 2016-2018. El propósito de este análisis es aportar al entendimiento del vínculo entre economías informales e ilegales y la política.

Conocer el verdadero poder que tiene el dinero en la política es de suma importancia, ya que independientemente de su origen, puede lograr cuanto menos, condicionar el accionar de las instituciones estatales a su favor. Por ello, la presente busca profundizar en el poder de un tipo de actor que es crucial para el entendimiento de nuestra política: el financista. Este es uno de los grandes aportantes privados de una campaña electoral. Es decir, una persona natural con gran influencia económica, empresa influyente o, en el caso del caso investigado, una actividad ilícita encubierta como otros tipos de aportes. Sobre esta última, las minerías ilícitas funcionan como un gran ejemplo para analizar la relación entre este tipo de intereses y el financiamiento de campañas políticas. Devela, pues, diversos mecanismos que se logran instaurar en un sistema poco regulado y con grandes falencias para lograr su cometido, que sería obtener la defensa de sus intereses a cambio del dinero ofrecido en tiempos de campaña. 
Antes de adentrarme en especificaciones, es importante decir que, con la reciente explosión mediática sobre el caso Odebrecht en la política peruana, donde se develó la existencia de un vínculo entre los aportes financieros por parte de la trasnacional a diversos personajes políticos con el fin de ganar licitaciones y crear una barrera de protección por medio de la compra de Jueces y otros personajes del Poder Judicial (Durand 2018: 15-20), se demuestra que el caso del financiamiento de campañas es clave para el entendimiento de los mecanismos de ingreso de dinero en la política, pero no es el único. Quiere decir que el dinero también puede ingresar por medio de "coimas" o intercambio de favores, mecanismos similares a los usados por Odebrecht y otros personajes con gran capacidad económica que han direccionado nuestra política nacional a su favor. Por otro lado, a pesar de que no todos los financistas reales figuran en la lista de aportantes en la campaña, entregada a la ONPE por Fuerza Popular, se sabe que existe una gran proporción monetaria "anónima" dentro del dinero recibido por este partido. A pesar de que esté de acuerdo con la afirmación de involucramiento de dinero ilícito en las campañas políticas, no quiere decir que piense que todo ese dinero "camuflado" haya provenido necesariamente de fuentes ilícitas o ilegales, ya que podría provenir de cualquier lugar.

Un punto importante es la existencia de la falta de un reglamento adecuado sobre el financiamiento de campañas políticas frente a los costos de las mismas. Se ignora pues, en la reglamentación actual, e incluso en mayor medida en la reglamentación vigente en la campaña general del 2016, que las campañas con cada elección son más caras y casi imposibles de costear, por lo cual se necesita una gran cantidad de dinero. Este dinero es a menudo cubierto bajo la etiqueta de actividades proselitistas como en el emblemático caso de los cocteles de Keiko Fujimori. Las fuentes de dinero pueden ser, sin duda, parcialmente ilícitas, pero también de fuentes lícitas que deben ser ocultas por la existencia restricciones absurdas sobre los montos que el sector privado puede donar.

El caso de estudio es la bancada fujimorista pues, teniendo la mayoría en el Congreso, la defensa de intereses al presentar proyectos de ley, les ha resultado más fácil a ellos que a otros grupos minoritarios del Parlamento. Con esto, es importante dejar en claro 
que Fuerza Popular no es, necesariamente, la única organización que defienda los intereses de quienes aportaron a su campaña electoral ni tampoco, como se mencionó antes, que el Poder Legislativo sea la única rama del estado que se ve inmersa en esta actividad motivada por intereses económicos. La vulnerabilidad de los partidos políticos frente al dinero (sin afán de victimizarlos) atenta directamente con la institucionalidad de estos y de las instituciones a las que pertenecen. En el contexto de un sistema de partidos bastante venido a menos desde la transición democrática, se facilita la infiltración de intereses por diversos mecanismos como el que pretendo analizar. Asimismo, no se da la relevancia suficiente a las investigaciones sobre financiamiento, pues suelen ser evitadas o al menos no son profundizadas debido a la perspectiva que parte de la concepción de la inevitable relación de estas con dinero ilícito y, por ende, con la expandida corrupción que aqueja a todos los países, principalmente en América Latina. Esta investigación, contrariamente, nace de la idea de que esa debería ser la razón principal para tratar más ese sector evitado de la política, contrario a rendirse ante este contexto. Mientras más visibilidad gana un tema en particular, es más difícil mantener ocultos casos concretos, como en este caso con vínculos directos a actividades ilícitas y a su vez, se incentiva el interés de la población frente a este tema, lo cual supone una lucha activa desde la sociedad civil en contra de la corrupción.

Con el fin de comprobar que el vínculo entre los grandes aportantes (registrados) y episodios donde se ve una sospechosa defensa de interés con ganancias aparentemente unilaterales, esta investigación busca ilustrar un caso en particular, el cual se respalda en la información accesible del financiamiento de la campaña general del año 2016. Este es, además, un caso que ejemplifica otras actividades ilícitas que se ven, a menudo, involucradas en la política. La presente investigación, solo analizará a la minería ilícita debido a la existencia de pruebas más claras de financiamiento y un pacto firmado en tiempos de campaña por la lideresa de Fuerza Popular.

\section{Elementos teóricos y contextuales:}

Si bien la investigación parte de las implicancias normativas de las campañas políticas, continúa analizando la situación del estado frente a los intereses económicos analizados en la presente 
investigación. Con ese fin, se utiliza la teoría de captura del estado y, en particular la de dos de sus mecanismos: el lobby y el financiamiento, los cuales permiten analizar el fenómeno de una mejor manera para asegurar así el mejor entendimiento posible antes de revisar los respectivos casos.

Como se mencionó anteriormente, la base de la investigación, el financiamiento de campañas, incluye facciones como los actores relacionados, la normativa detrás e incluso las irregularidades, que suelen ser tomadas desde una perspectiva que oscila mayormente entre lo estructural o lo institucional. Desde el primer enfoque, se trata de una perspectiva a la cual se le suele atribuir, al orden o estructura político o social, una serie de factores de comportamiento y relación de actores que terminan viéndose reflejados en la estructura. (Castiglioni y Fuentes 2015: 16-17) Dicha estructura, según esta perspectiva y aterrizando al tema en concreto, explica la manera en la que las relaciones entre los actores involucrados en el financiamiento de campaña se dan. Desde la perspectiva institucional suele atribuirse a las instituciones el control de la situación a tratar como entes reguladores. Este enfoque considera a las instituciones como reglas de funcionamiento de la sociedad. Los institucionalistas describen las instituciones como acción de gobierno en los campos organizacionales, las instituciones son consideradas como recursos de los agentes y actores racionales para obtener el logro de sus objetivos. Para los institucionalistas, la cooperación se sostiene a través de mecanismos iterativos en los que la amenaza de replicación junto con la facilitación de flujos de información y mecanismos de monitoreo detienen los peligros. Las instituciones son puntos focales para la cooperación, proveen tareas de monitoreo e información, que entregan ganancias distribucionales. (Vargas 2008).

Es importante entender tanto los riesgos a los que se enfrenta como el contexto en el que se sitúa el Perú para lograr entender el papel de los financistas. Conocer las vulnerabilidades del territorio peruano frente a economías ilícitas, ayuda a comprender que el poder del dinero en la política, previamente analizado, se vuelve todavía más peligroso ya que este puede venir de, no solo fuentes privadas que busquen beneficiarse, sino también de actividades que oscilan entre lo ilícito y lo ilegal. "En América Latina el mayor peligro es que el narcotráfico -y el crimen organizado en general- penetre las 
instancias políticas para comprar impunidad mediante el financiamiento de campañas" (Casas y Zovatto 2011: 50-52). En el caso peruano en particular, esto se suma a la alta producción de coca, de la cual más de $90 \%$-según la Oficina de las Naciones Unidad en contra la droga y el delito- es destinado a la producción de pasta básica de cocaína o clorhidrato de cocaína. El amplio territorio rico en minerales y la gran cantidad de fronteras son algunos de los elementos que vuelven al país particularmente vulnerable ante este tipo de economías (2017) en particular al narcotráfico y al caso particular de la presente investigación, la minería ilegal o informal. Asimismo, esta penetración puede causar la formación de una barrera cuasi-irrompible debido a su capacidad de adaptación en las instituciones encargadas de prevenir, monitorear, y fiscalizar las irregularidades dentro de las elecciones como lo es el caso de la ONPE y en particular, su Gerencia de Supervisión de Fondos Partidarios. El dinero es, pues, una fuente que otorga poder a los partidos candidatos frente a sus oponentes $y$, a los financistas se les da "una posibilidad diferenciada de participar en elecciones y ejercer su influencia sobre los candidatos y partidos, a través de sus contribuciones". (Casa y Zovatto 2010:49) La influencia del dinero en la campaña electoral tiene un impacto direccionador en las futuras decisiones políticas, además de la permanente baja institucionalización de los partidos políticos y la alta desconfianza hacia ellos que, a su vez, aleja la posibilidad de una activa fiscalización desde la sociedad civil.

Para entender mejor el fenómeno, la presente investigación parte de la definición de sistema de financiamiento partidario de Zovatto, quien lo describe como el conjunto de normas formales que regulan la financiación del partido. (2015) Sin embargo, es importante sumar la definición del término que lo describe como la posesión de recursos y la manera en cómo se regula afecta la institucionalización de los partidos (Zavaleta y Vilca: 2017) Por otro lado, si bien existen normas que se proponen regularlo, $y$, por ende, también al creciente poder de los financistas, existen notorios vacíos legales que estimulan la penetración de fondos ilícitos disfrazados de lícitos. (Tuesta 2011:455) Siguiendo esta línea, el análisis se basa en el tipo de financiamiento privado, el cual propició las defensas de intereses a manos de los congresistas fujimoristas. Para evaluar las implicancias de este tipo de financiamiento, es necesario entender el 
concepto de transparencia. Sobre ella, es importante decir que supone su uso para reportar a las campañas y las fuentes y/o el uso del dinero obtenido de diversas fuentes. La definición de transparencia que se utiliza en la presente investigación, ha sido elegida para poder facilitar la identificación de sanciones, tales como multas, retención de subsidios, remoción de inscripción a los partidos políticos, entre otros. (Casas y Zovatto 2015) Respecto a los riesgos entorno a la desigual distribución del dinero en la política, es crucial entender los precios de la propaganda común de una campaña electoral para entender el poder que tienen los financistas de estas. Según Zavaleta y Vilca, este poder suele provenir del dinero en grandes cantidades, sea este lícito o ilícito. (2017) Asimismo, este poder puede facilitar la cooptación o captura del estado, la compra de influencias, $y$, más puntualmente, un tema en el que planeo ahondar en la presente, la pérdida de legitimidad o institucionalización partidaria como parte de un amplio proceso de captura del estado (Durand: 2016).

Siendo esta una investigación que se basa en el impacto de un tipo de actor en particular, es importante profundizar en su definición. Con el término "financistas de campañas", se hace referencia a personas o entidades privadas con poder económico (independientemente de ser este lícito o no) quienes aportan dinero a la campaña política de uno o más partidos basados en las oportunidades del candidato para ganar, la cantidad de dinero que se posee $y$, a pesar de ser cuestionada la existencia de esta en la actualidad, la ideología defendida por el partido. Este último factor se relaciona a los intereses de este actor, o del caso contrario, se financia a un partido con el fin de que no salga elegido otro, con ideas opuestas a los intereses de los financistas. Siguiendo esta línea, Joeal S. Migdal ofrece una mirada a las alturas del estado, que en la presente investigación se ven abordadas desde el Poder Legislativo, y su relación con intereses externos. "A menudo quienes están en las oficinas centrales deben tratar con las fuerzas más poderosas de la sociedad fuera de la organización Estatal" (2011: 158). El poder de estos grupos se ve incrementado por la influencia económica que tengan. Frente a ello, la base teórica de mi investigación parte de dos teorías similares entre sí. 
Por un lado, la noción de captura del estado, y en particular el lobby por medio del financiamiento, como su mecanismo habla de la influencia de grupos poderosos en la toma de decisiones en el estado (Durand: 2016) Se defienden no solo poderes formales del sector privado, sino también informales, como lo es la minería ilícita en la que profundizaré. Por ello, es importante agregar otra teoría que se base más en el poder de estos tipos de fuerzas. El concepto definido por Schultze-Kraft, la crimilegalidad, ofrece una interpretación de la corrupción, partiendo de la idea de que esta no ataca o reemplaza al estado (a diferencia de lo planteado por la captura del estado) sino que coexisten e incluso una depende de la otra. Es importante recalcar que este enfoque habla de las actividades ilícitas específicamente y por ende es solo aplicable para los casos de financiamiento en los que se sospeche un involucramiento de dinero proveniente de actividades criminales. Por ende, ambas perspectivas para el desarrollo de la presente son importantes.

"La captura del estado florece bajo el neoliberalismo y allana el camino hacia la extrema concentración del poder económico (una de las variables independientes clave), proceso que se introduce sin mayor debate y que se refuerza con el autoritarismo. (...) con el retorno de la democracia, recurren a otros instrumentos, como la financiación de campañas y el lobby, para lograr darle continuidad a la captura del estado. La meta principal de los actores económicos más poderosos es tener una influencia directa y permanente en áreas claves del gobierno que tienen que ver con los asuntos económicos. Hacen esto con el fin de generar políticas, prevenir cambios, monitorear su implementación y defender "derechos adquiridos»" (Durand: 2012 24-25)

Es decir, si bien se conoce de la existencia de ambos mecanismos en nuestro estado, son pocos los intentos de analizarlos a fondo y de regularlos. Sobre esto, una de las partes importantes para esta investigación su conceptualización. Es decir, es posible hablar de lobby cuando se financia una campaña y se tiene pretensiones de ver sus intereses defendidos en el legislativo, como presenta el caso al que trataré. Sin embargo, es importante aclarar que el lobista no siempre obtiene lo que quiere ya que esta es una práctica corrupta abiertamente (Durand: 2017 68-69). Si bien no se cuenta con las 
evidencias o mecanismos necesarios para juzgar a los involucrados, se puede lograr evidenciar la defensa de intereses de grupos muy particulares expuestos en algunos proyectos de pey presentados, bloqueados o aprobados por la bancada fujimorista. Con esto, se puede lograr hacer una conexión entre los vacíos de financiamientos similares al caso de los cócteles de las elecciones del 2011 o las confesiones de Jorge Barata respecto a aportes millonarios a campañas políticas que son recientemente investigadas, y en el particular de la presente investigación, los intereses de las mineras ilícitas que se han visto defendidos en el proyecto de ley a analizar.

Retomando el concepto que fue mencionado con anterioridad, sobre la crimilegalidad, Markus Schultze-Kraft, el autor de este término, lo percibe como:

"Un conjunto de patrones regulares de intercambio e interacción social entre el estado y actores no estatales, públicos y privados que se sitúan en los márgenes de, o están flagrantemente en contravención a la ley establecida en un lugar y momento dado. Estos intercambios e interacciones sociales están situados en las zonas grises que se encuentran en algún lugar del continuo que se extiende desde el ámbito de la legalidad hasta el de la criminalidad. Si bien estos intercambios e interacciones pueden estar $-\mathrm{y}$ en realidad lo están a menudo- orientados a generar ganancias económicas privadas, individuales o colectivas, también producen legitimidad, exoneración judicial y, en última instancia, orden político y social." (2016:34)

Los enfoques y conceptos desarrollados ayudan a analizar a los financistas en el contexto de las elecciones 2016 y su impacto en el legislativo hasta la presentación del proyecto de ley que analizaré más adelante en esta investigación.

\section{Análisis del caso}

Como se ha venido exponiendo, el caso peruano es emblemático en temas de desigualdad en la participación política. La diferencia entre los aportes económicos en las campañas electorales se puede señalar como una ventaja marcada por razones principalmente monetarias 
gracias a la compra de influencias. Dicho esto, el caso seleccionado ofrece una clara mirada al financiamiento de campaña y cómo este constituye un mecanismo que mantiene una desigualdad tanto en la participación como la representación política. La hipótesis principal es que los grandes poderes económicos ejercen influencias políticas por el medio de diversas estrategias entre las cuales se encuentra el financiamiento de campañas electorales. De esta manera, el poder de estos personajes se ve incrementado y se torna en importantes direccionadores de nuestra política nacional. Con esto no se quiere decir que el financiamiento de campañas sea la única manera en la que estos actores consiguen una presencia en el rumbo de la política. Como se dijo en párrafos anteriores, los mecanismos son diversos, pero, en el caso de Fuerza Popular y, en particular en el caso seleccionado, el vínculo de financiamiento es el más fuerte y el que explica la defensa de intereses de estos grupos desde el Poder Legislativo. A continuación, se detallará a mayor profundidad el caso que refuerza la hipótesis.

La vulnerabilidad del país frente a las economías ilícitas sumada a la faltante reglamentación del financiamiento de campañas ha permitido por muchos años que se normalice el utilizar distintos mecanismos para ocultar dinero que excede los montos permitidos o que proviene de origen sospechoso. Las regiones que son escenario de dichas actividades son particularmente vulnerables en sus gobiernos y municipalidades.

Es así como regiones víctimas de tala ilegal, minería ilícita, contrabando, narcotráfico, trata de personas, entre otras actividades ilícitas, suelen ser los lugares en dónde se presentan estas actividades con el fin de mantener el funcionamiento de sus instancias de poder a favor de los intereses de dichas actividades para mantener así su pleno funcionamiento y expansión. Sin embargo, la captura de gobiernos regionales y locales no los cubre de la reglamentación nacional. Es verdad que la regulación de estas zonas afectadas por diversas economías ilícitas se mantiene baja al igual que cualquier tipo de incidencia estatal, pero el blindaje de sus involucrados debe ser más transversal, es decir, incluir al gobierno central y sus poderes.

La minería ilícita, como caso de esta investigación puede ser detectada en las esferas ya mencionadas, y a pesar de esto, parece 
ser muy poco combatida, y si lo es obtiene muy pocos resultados a favor del estado. Al igual como sucedió con el ascenso de la captura del estado y sus mecanismos con la introducción de las políticas neoliberales en los 90's (Durand 2012). En la misma década, es decir, durante el periodo de gobierno de Alberto Fujimori, la implementación de las políticas neoliberales creó un escenario en el que, con la que se disminuyó el papel estatal para la producción y con ello la privatización de grandes empresas que venían siendo estatales. Así mismo, se permitiría con mayor flexibilidad ciertas actividades entre las cueles se encuentra la minería ilícita con el fin de atraer una mayor inversión extranjera. Dentro de los beneficios, se encontró el otorgamiento de excepción de impuestos a grandes proyectos extractivos. (Damonte 2016: 960-961) Con este tipo de incentivos, se fue creando una regulación promotora de intereses privados que beneficiaron la expansión de la exploración y explotación de zonas ricas en minerales como lo es Madre de Dios. (Glave y Kuramoto 2007) Bajo este contexto, la cantidad de mineras informales aumentó potencialmente con el pasar de los años, esta situación llegó a ser casi incontrolable. El tamaño y el poder de las empresas mineras ilícitas varía mucho, pero todos se ven beneficiadas gracias a la baja regulación estatal. Al tratarse de un tema que afecta tanto a los pobladores de las zonas afectadas como al medio ambiente al no regirse bajo las normas internacionales, este se ha mantenido como un tema urgente que debe ser solucionado.

Con el pasar de los años tras la caída de Alberto Fujimori, los gobiernos han mantenido la promesa de formalizar a dichas empresas con el fin de reducir sus impactos negativos. Han existido amplias campañas represivas sustentadas con un gran apoyo popular, pero todas sin éxito. Las grandes movilizaciones de este sector han significado constantes retrocesos en los intentos de los gobiernos que han existido desde el fin del gobierno de Fujimori.

"Sin embargo, el gobierno sigue siendo políticamente e institucionalmente incapaz para lidiar con actividades extractivas informales a pequeña escala. Primero, el consenso extractivo estatal, que apoya la minería a gran escala, no incluye actividades de pequeña escala. Mientras que el Ministerio de Minería y Energía intenta encontrar el para formalizar a los mineros, el Ministerio de Medio 
Ambiente quiere traer estas actividades al alto en el Amazonas. En segundo lugar, dado que las agencias centrales del estado responsables de regular a las extractivas a gran escala no tienen políticas o instrumentos para regular a los mineros en pequeña escala, el estado ha recurrido a transferir la responsabilidad de la implementación y monitoreo del plan de formalización al gobierno regional en Madre de Dios. Sin embargo, El gobierno central no ha asignado suficientes fondos, información y /o capacidades técnicas a esta oficina regional para hacer frente a la tarea encomendada (León 2012 en Damonte 2016: 966).

El gobierno de Ollanta Humala, gobierno anterior al que se constituye en el marco temporal de esta investigación, mantuvo un discurso rígido en contra de esta actividad y, si bien lo logró mayores cambios estructurales, sí aumentó ciertas regulaciones con los Decretos Legislativos № 1100, 1101, 1102, 1103, 1105 y 1107, los cuales facilitaron el inicio de investigaciones a personas involucradas, como en el caso en el que profundizaré más adelante sobre Modesto Figueroa, congresista por Fuerza Popular en el periodo actual y gran financista de su campaña general en el 2016.

La minera tanto legal como ilegal se ha visto involucrada en las campañas presidenciales de Keiko Fujimori. Madeleine Osterling Letts, excandidata a la alcaldía de San Isidro por Fuerza Popular, quien figura como una de las mayores aportantes de la campaña de este partido en el 2016 con S/ 169.250 (Ojo Público), es también directora de la Minera Volcán, que, si bien no es ilegal, es considerada como la más infractora a las normas mineras del país. Por otro lado, la congresista Úrsula Letona creó en el año 2012 la Minera Rana 34 S.A.C., la cual cuenta con mineros informales entre sus trabajadores. A pesar de que la congresista dejó la dirección de dicha minera, sus vínculos con la misma son innegables. Ambos casos demuestran un involucramiento entre la minería informal (o infractora) y Fuerza Popular.

En particular, las mineras informales e ilegales son múltiples veces vinculadas a la captura de gobiernos regionales y locales como ya se dijo, y en el caso de las campañas nacionales, como sucede en el caso 
presentado. Además del vínculo del financiamiento, la defensa sus intereses desde el Congreso de la República se dio con la presentación del proyecto de ley $\mathrm{N}^{\circ} 1095 / 2016-\mathrm{CR}$, presentado por la congresista Alejandra Aramayo, donde se propuso eliminar a las mineras ilícitas de la ley contra el crimen organizado, beneficiando así a este sector con la reducción de penas y multas. Tanto el financiamiento como la defensa de intereses se ven graficados en el siguiente mapa:

Grafico 1. Mapas de financiamiento y defensa de intereses

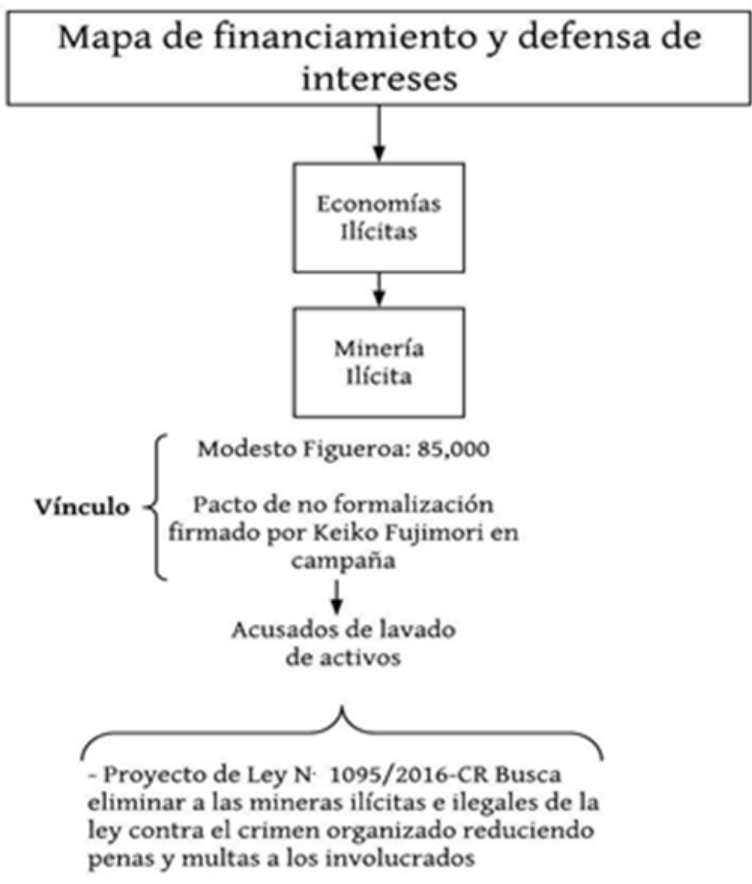

Elaboración propia sobre la base de la ONPE, Congreso de la República y Díaz (2017)

El vínculo entre las mineras ilícitas y Fuerza Popular se identifica con claridad en el caso del ya mencionado congresista de Madre de Dios, Modesto Figueroa quien pertenece también a la bancada fujimorista y está siendo investigado por enriquecimiento ilícito, por involucramientos con minería ilegal, por transportar petróleo para la 
minería ilegal, tener un grifo en Madre de Dios el cual lo comercializaba y por lavado de activos a través de sus empresas. La acusación de enriquecimiento ilícito parte del inexplicable aumento patrimonial desde los años noventa donde dejó de ser un transportista informal de mototaxi en la región a contar con varias empresas a su nombre, como también facturar grandes cantidades de dinero. Según la sección de aportes limpios de la ONPE, este congresista aportó 85 mil nuevos soles entre dinero en efectivo y especies a la campaña general del fujimorismo en el 2016. Si bien no es el aporte más cuantioso de la campaña general de dicho partido, significa un monto importante de dinero y más conociendo su proveniencia oscura e incierta.

En paralelo, la entonces candidata Keiko Fujimori, en abril del 2016 "firmó un acuerdo con los mineros ilegales de Madre de Dios comprometiéndose a derogar los decretos que promovían la formalización y determinaban la ilegalidad de sus actividades." (Díaz 2017) La lideresa de Fuerza Popular acudió al lado de Úrsula Letona (cuyo vínculo con esta actividad económica fue analizado en líneas anteriores) a la reunión en el local de la Molina de este partido, en donde acudieron diversos representantes de mineras informales y se presentaron abiertamente en contra de las reglamentaciones rígidas que suponía el gobierno de Ollanta Humala que iba terminando. Con el proyecto de ley presentado por la congresista Aramayo, se puede reconocer un intento de cumplir con lo pactado con el grupo de mineras ilícitas que a continuación paso a detallar.

El proyecto de ley supone la eliminación de la minería ilícita de la Ley contra el Crimen Organizado y cambiaría las consecuencias de dicha actividad como se encuentran expresas en el artículo 317 de la mencionada norma. En dicha ley se establece que se considera una asociación ilícita:

"El que constituya, promueva o integre una organización de dos o más personas destinada a cometer delitos será reprimido con pena privativa de libertad no menor de tres ni mayor de seis años. La pena será no menor de ocho ni mayor de quince años, de ciento ochenta a trescientos sesenta y cinco días-multas e inhabilitación conforme a los incisos 1), 2) y 4) del artículo 36 , imponiéndose, además, de ser el caso, las 
consecuencias accesorias previstas en los incisos 2 y 4 del artículo 105, debiéndose dictar las medidas cautelares que correspondan, en los siguientes caso" (Ley №30077, art. 317)

De la misma manera, el proyecto de ley busca dejar sin efecto la modificación del Artículo $307^{\circ}$-A sobre el delito de minería ilegal en el Código Penal el cual establece que:

"Será reprimido con pena privativa de libertad no menor de cuatro años ni mayor de ocho años y con cien a seiscientos días-multa, el que realice actividad de exploración, extracción, explotación u otros actos similares, de recursos minerales, metálicos o no metálicos, sin contar con la autorización de la entidad administrativa competente, que cause o pueda causar perjuicio, alteración o daño al ambiente o sus componentes, la calidad o la salud ambientales. Si el agente actuó por culpa, la pena será privativa de libertad no mayor de tres años o con prestación de servicios comunitarios de cuarenta a ochenta jornadas." (Código Penal Peruano, art. 307-A)

De esta manera, las mineras ilícitas se vieron defendidas desde el Poder Legislativo durante el periodo en el que Fuerza popular gozaba con mayoría parlamentaria. Si bien el proyecto de ley analizado se ha mantenido en la Comisión de Justicia y Derechos Humanos, es importante tratarlo porque demuestra una clara defensa de intereses a un sector que se encuentra involucrado en el financiamiento de la campaña que logró brindarle la mayoría absoluta a Fuerza Popular en el Congreso de la República.

\section{Comentarios finales}

Este artículo ha buscado profundizar en el entendimiento del fenómeno del financiamiento político como herramienta de la captura estatal y cómo este estimula el sostenimiento de una estructura en la que los poderes económicos son quienes logran mayor representatividad en el estado a pesar de tratarse, en algunos casos, de actividades ilícitas. El poder de los financistas se ha visto acrecentado debido a la baja regulación. Es así como, en el contexto de un sistema de partidos debilitado, la necesidad de generar votos, 
los partidos se vuelven particularmente influenciados por intereses diversos al momento de conseguir fuentes de ingreso monetario para su campaña. Recientemente implementado, el financiamiento público directo, ha cumplido una meta trazada desde el marco legal del 2003, sumándose al financiamiento público indirecto a través de la franja electoral en los medios de comunicación. A pesar de ello, los montos ofrecidos a los partidos con representación en el congreso no se acercan remotamente a los costos que se manejan en las campañas actuales. Por otro lado, este dinero no puede ser utilizado para las campañas políticas, sino solamente para gastos administrativos y de capacitación.

Asimismo, la reciente aprobación de las reformas del Referéndum 2018 y, en particular, sobre la regulación del financiamiento de organizaciones políticas que fue ampliamente aprobada por la población con un $85.78 \%$ de votos válidos (ONPE) se añadió a la verificación, control y sanción como responsabilidad dentro de la Constitución. Es decir, al infringir las normas de financiamiento, las sanciones a los partidos políticos dejan de estar en la ley de organizaciones políticas y pasan a rango constitucional. Con esto, finalmente el financiamiento partidario y las implicancias del mismo son tomados como el problema crucial que significan y marcan una nueva meta dentro de los cambios a ser incluidos para las próximas elecciones. Sin embargo, para efectos de esta investigación, la ley no incluía en el año 2016 ninguno de los dos mecanismos mencionados, ya que faltaba ponerse a prueba en elecciones generales $y$, por ello, la necesidad de obtener financiamiento de otras fuentes como la analizada en el presente texto se constituyó en un mecanismo casi normalizado.

Finalmente, si bien el proyecto de ley presentado por la congresista Aramayo no ha sido aprobado, refleja el gran poder de los actores que inyectan dinero a las campañas con el objetivo de introducir temas en agenda. Al tratarse de una economía ilícita, el caso logró gran cobertura en los medios de comunicación, lo cual refuerza la tesis de la capacidad de estos para, en este caso, lograr evitar la continuación del recorrido legislativo para que dichos intereses logren constituirse en una ley (Urteaga 2017). Esto se muestra, como ejemplo de defensa de intereses en la actualidad o, cuanto menos como un precedente a casos futuros en los que los mismos intereses 
logren verse defendidos a través del legislativo y demuestra la gran capacidad de los agentes de captura para posicionar sus intereses (Durand 2018). Esta investigación constituye un acercamiento que ayuda a entender el funcionamiento real de nuestra política nacional. Las falencias de representación que existen y cómo estas se ven incrementadas y reforzadas gracias a la intervención de grupos de gran poder adquisitivo proveniente de actividades económicas ilícitas. Estas intervenciones colaboran con el deterioro de la calidad de vida de muchos peruanos, el medio ambiente, y la calidad institucional de nuestro Estado.

\section{Bibliografía}

Aramayo, A. (2016) Proyecto de Ley 1095/2016-CR

Casas, K., y Zovatto, D. (2015). El costo de la democracia. Apuntes sobre la regulación del financiamiento político en América Latina. Latin American Initiative, Foreign Policy.

Castellani, A. (2018). Lobbies y puertas giratorias: Los riesgos de la captura de la decisión pública. Nueva Sociedad, (276), 48-61.

Castiglioni, R., y Fuentes, C. (Eds.). (2015). Política comparada sobre América Latina: teorías, métodos y tópicos. Ediciones Universidad Diego Portales.

CONGRESO DE LA REPÚBLICA DEL PERÚ Consulta: 07 de mayo de 2019 http://www.congreso.gob.pe

Damonte, G. H. (2016). The “Blind” State: Government Quest for Formalization and Conflict with Small-Scale Miners in the Peruvian Amazon. Antipode, 48(4), 956-976.

Damonte, G. H. (2018). Mining Formalization at the Margins of the State: Small-scale Miners and State Governance in the Peruvian Amazon. Development and Change, 49(5), 1314-1335.

Diario Oficial El Peruano 
(1997) Ley $N^{\circ} 26859$, Ley Orgánica de Elecciones, Diario Oficial El Peruano, 29 de setiembre de 1997

(2003) Ley $\mathrm{N}^{\circ}$ 28094, Ley de Partidos Políticos, Diario Oficial El Peruano, 31 de octubre de 2003

(2005) Resolución Jefatural № 060-2005-J/ONPE Reglamento de Financiamiento y Supervisión de Fondos Partidarios, Diario Oficial El Peruano, 16 de marzo de 2005.

(2010) Resolución No. 136-2010-JNE Reglamento de propaganda electoral, Diario Oficial El Peruano, 26 de febrero de 2010.

(2013) Ley N 30077 Ley contra el Crimen Organizado, Diario Oficial El Peruano, 20 de agosto de 2013

Durand, F. (2012). El debate sobre la captura del Estado peruano. Perú Hoy: la gran continuidad, Lima: DESCO, 19-56.

Durand, F. (2016). Cuando el Poder Extractivo Captura el Estado: Lobbies, puertas giratorias y paquetazo ambiental en Perú. Oxfam.

Durand, F. (2017). Doce apóstoles de la economía peruana. Fondo Editorial de la Pontificia Universidad Católica de Perú.

Durand, F. (2018). Odebrecht: la empresa que capturaba gobiernos. Oxfam.

Glave, M. y Kuramoto, J. (2007) La minería peruana: lo que sabemos y lo que aún nos falta por saber. Investigación, políticas y desarrollo en el Perú. pp. 135-181.

Casas, K., \& Zovatto, D. (2011). Para llegar a tiempo: apuntes sobre la regulación del financiamiento político en América Latina Organización de los Estados Americanos, pp. 17-67.

Migdal, J. (2011) Estados débiles, estados fuertes, México, Fondo de Cultura Económica.

OFICINA NACIONAL DE PROCESOS ELECTORALES Página web de la ONPE.Consultada el 22 de mayo del 
2019. https://www.web.onpe.gob.pe/servicios/financiamientoorganizaciones-politicas/aportes-limpios/

Schultze-Kraft, Markus. 2016. Órdenes crimilegales: repensando el poder político del crimen organizado. Iconos, 20/2(55):25-44.

Díaz, J. (2017) ¿Por qué el fujimorismo busca beneficiar a los mineros ilegales? Recuperado de: https://www.servindi.org/actualidadnoticias/02/05/2017/por-que-el-fujimorismo-busca-beneficiarlos-mineros-ilegales

Tuesta, F. (2011). El financiamiento de los partidos políticos en el Perú. En Financiamiento de los partidos políticos en América Latina, Instituto de Investigaciones Jurídicas, pp. 445-482.

Tuesta, F. (2017) Perú: Elecciones 2016 Un país dividido y un resultado inesperado. PUCP

UNODC (2017) Monitoreo de Cultivos de Coca. Lima

Urteaga, M. (2017) Cuando los poderosos pierden: Poder empresarial y regulación del cultivo de semillas transgénicas en el Perú (tesis de licenciatura). Pontificia Universidad Católica del Perú, Lima.

Vargas, J. (2008) Perspectivas del Institucionalismo y Neoinstitucionalismo. En Ciencia Administrativa 2008(1), pp. 4758

Zavaleta, M. y Vilca, P. (2017) Partidos nacionales, políticos locales: una mirada a las candidaturas parlamentarias desde el sur del Perú. En Tuesta, F. (2017): Perú: Elecciones 2016. Un país dividido y un resultado inesperado. Fondo Editorial de la PUCP.

Zovatto, D. (2014) Reflexión comparada sobre el financiamiento político público. En ONPE (2014) Financiamiento Político en el Perú. Lima: Biblioteca Nacional del Perú, pp. 21-65. 